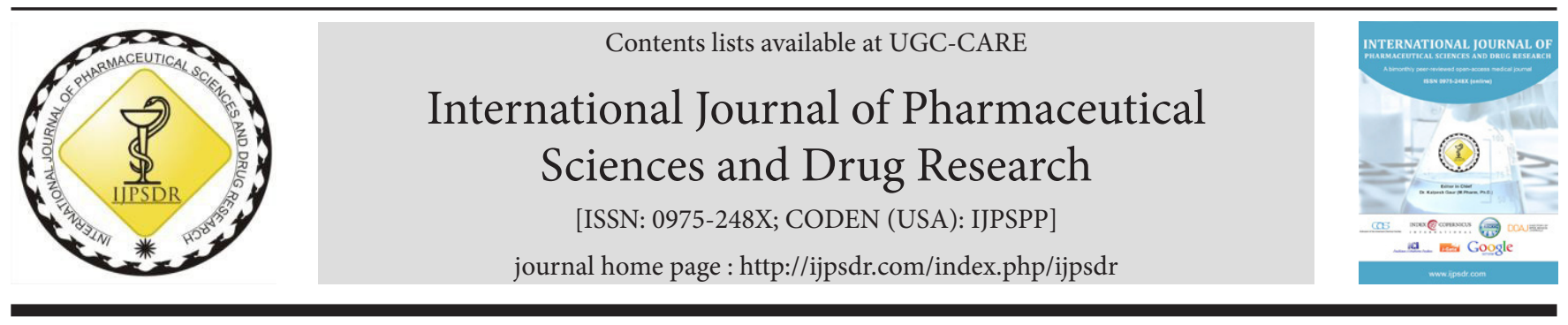

Research Article

\title{
Antibacterial Activity of Desiccated Cyanobacterium Anabaena sp. Isolated from Terracotta Monuments of Bishnupur, West Bengal
}

\author{
Shailen Bhakat ${ }^{1}$, Subarna Saha ${ }^{1}$, Sikha Mandal $^{2}$, Jnanendra Rath ${ }^{1 *}$ \\ ${ }^{1}$ Department of Botany, Visva-Bharati University, Santiniketan-731235, West Bengal, India \\ ${ }^{2}$ Department of Botany, Sree Chaitanya College, Habra-743268, West Bengal, India
}

\begin{tabular}{l} 
A R T I C L E I N F O \\
\hline Article history: \\
Received: 29 October, 2019 \\
Revised: 29 January, 2020 \\
Accepted: 12 February, 2020 \\
Published: 30 March, 2020 \\
Keywords: \\
Anabaena, \\
Antibacterial, \\
Desiccation, MIC, \\
Sub-aerial cyanobacteria. \\
D0I: \\
10.25004/IJPSDR.2020.120201
\end{tabular}

\section{INTRODUCTION}

Multidrug-resistance to the pathogenic bacteria is a great concern for public health throughout the world. The routinely used drugs against many clinical pathogens such as Mycobacterium tuberculosis, Enterococcus, Pseudomonas sp., Streptococcus pneumoniae, and Staphylococcus aureus are not working. To overcome this alarming situation novel antibacterial product development from unknown sources is the need of the hour. Cyanobacteria, photosynthetic prokaryotes are a prolific source of natural products with a great choice for new drug developments in biotechnology and pharmaceutical industries. Cyanobacteria being able to tolerate many stresses and found in extreme climatic conditions, is a very potential candidate for novel drug discovery. ${ }^{[1-3]}$ Many cyanobacteria occurred in desiccated state on sub-aerial surfaces like ancient monuments and building facades. Anabaena sp. is one of the subaerial cyanobacterium, which can survive in desiccated conditions. Many of the subaerial cyanobacteria are having polysaccharide covering in the form of slime, capsule or sheath, which acts as a protective boundary between the cells and its surrounding environment. ${ }^{[4-5]}$ Among cyanobacteria, marine cyanobacteria are studied well for their bioactive metabolites and till now 569 natural products have been reported in MarinLit ${ }^{[6]}$ from them. However, bioactive metabolites of sub-aerial cyanobacteria are not well known. Since in subaerial environment cyanobacteria have to adapt a wide variation of stresses, they might have produced some novel antimicrobial compounds. Therefore we have initiated this study with objectives of isolation and culture of subaerial

\footnotetext{
*Corresponding Author: Dr. Jnanendra Rath

Address: Department of Botany, Visva-Bharati University, Santiniketan-731235, West Bengal, India

Email $\bowtie$ : jrath@visva-bharati.ac.in

Tel.: +91-8240071294

Relevant conflicts of interest/financial disclosures: The authors declare that the research was conducted in the absence of any commercial or financial relationships that could be construed as a potential conflict of interest.

Copyright (C) 2020 Shailen Bhakat et al. This is an open access article distributed under the terms of the Creative Commons Attribution- NonCommercialShareAlike 4.0 International License which allows others to remix, tweak, and build upon the work non-commercially, as long as the author is credited and the new creations are licensed under the identical terms.
} 
cyanobacteria and evaluate its anti-microbial properties against some pathogenic bacteria.

\section{Materials And Methods}

\section{Collection Site, Isolation, Growth Conditions and Identification}

Bishnupur temples are unique for its excellent terracotta works and located between $23^{\circ} 4^{\prime} 48^{\prime \prime} \mathrm{N}$ latitude and $87^{\circ} 19^{\prime} 12^{\prime \prime} \mathrm{E}$ longitude in Bankura districts of West Bengal. In these terracotta monuments cyanobacteria colonises and can withstand high temperature and desiccation conditions in the form of crusts. Cyanobacterial crust samples were collected from the Bishnupur terracotta using non-destructive double-sided tapes, and a pinch of the collected crust was soaked with 12-48 hours. When some bluish-green color appeared on the crust, it was transferred to BG-11 medium with $1.2 \% \mathrm{w} / \mathrm{v}$ agar with or without nitrogen sources and incubated with fluorescent light $\left(7.5 \mathrm{~W} / \mathrm{m}^{2}\right)$ at $25 \pm 1^{\circ} \mathrm{C} \cdot{ }^{[7]}$ After repeated sub-culturing, pure cultures of the cyanobacteria were established. The isolated cyanobacteria were observed using a trinocular research microscope (Leica DM 750) and microphotographs were taken using Leica EC3 scientific digital camera and further analyzed with LAS EZ software. Three Anabaena sp. [Anabaena sp. (VBCCA 052002), Anabaena sp. (VBCCA 052 009), and Anabaena sphaerica (VBCCA 052 010)], were isolated, assigned with a strain number, and the pure cultures were deposited in the Visva-Bharati Culture Collection of Algae (VBCCA) which is affiliated to the World Federation of Culture Collection (WDCM 931). The isolated cyanobacteria were identified using standard monographs. ${ }^{[8-11]}$

\section{Extraction and Fractionation of the Metabolites}

The isolated cyanobacteria were cultured in the batch culture system using the BG-11(-N) medium for 30 days and centrifuged at $10,000 \mathrm{rpm}$ for 10 minutes to get the cell biomass. The algal pellet was washed in distilled water to remove the salts and dried in a lyophilizer. Five grams of the respected dried cyanobacteria samples were extracted with $50 \mathrm{~mL}$ of ethyl acetate, ethyl alcohol, and water using a sonicated water bath for 30 minutes. The extracts were filtered and dried in a rotary vacuum evaporator under reduced pressure and treated as crude extracts. The crude extracts were dissolved in $1 \mathrm{~mL}$ Dimethyl sulfoxide (DMSO) and stored in $4^{\circ} \mathrm{C}$ for further anti-microbial studies. Crude extracts $(10 \mathrm{mg})$ of the metabolites are further fractionated using $\mathrm{LH}_{20}$ and silica column chromatography using standard National Institute of Health (NIH), USA fractionation scheme. In brief, the fractionations of crude extractes were carried out using silica column chromatography and eluted with non-polar to polar solvent systems such as hexane $(100 \%)$, hexane: ethyl acetate (50:50), ethyl acetate (100\%), ethyl acetate: methanol (50:50), methanol (100\%), and water (100\%).
Further purification of the metabolites was carried out using $\mathrm{LH}_{20}$ column chromatography and eluted with mobile phase chloroform (100\%), chloroform:methanol (50:50), methanol (100\%), and methanol:water (50:50). All the fractions were dried using a rotary vacuum evaporator, and antibacterial assay were carried out using crude as well as silica and $\mathrm{LH}_{20}$ fractions.

\section{Antibacterial Assay}

Antibacterial activates of crude and all the fractions of three Anabaena sp. were carried out using the agar well diffusion method. ${ }^{[12]}$ The five test pathogenic bacteria [Bacillus subtilis (MTCC 121), Listeria monocytogenes (MTCC 657), Staphylococcus aureus (MTCC 96), Salmonella typhimurium (MTCC 98), and Escherichia coli (MTCC 1667)] were procured from microbial type culture collection (MTCC), IMTech, Chandigarh. The bacterial test strains used were picked up from the agar slants and inoculated in freshly prepared slants and incubated inside an incubator with 28 or $37^{\circ} \mathrm{C}$ temperature. Further, the bacterial suspensions were evenly inoculated in nutrient agar (NA) plates and holes of $5 \mathrm{~mm}$ in diameter was punched aseptically with a sterile cork borer. In each well, $50 \mu \mathrm{L}$ of crude and the column fractions dissolved in DMSO were added and incubated at 28 or $37^{\circ} \mathrm{C}$ temperature. After 24 hour of incubation, the zone of inhibition was observed, and the diameter of zones of inhibition was measured in $\mathrm{mm}$. Ciprofloxacin $(100 \mu \mathrm{g} / \mathrm{mL})$ and DMSO were used as positive and negative control, respectively.

\section{Microtiter Plate-based Anti-microbial Assay}

Purified natural compounds are generally found in a very low amount, which can create some challenges for the bioassay. Therefore, we have also used a resazurin microtiter plate-based assay following a modified method of Sarker et al. 2007. ${ }^{[13]}$ In brief sterile 96 well microtiter plate is opened under aseptic condition. Several working concentrations of the crude extract were made and added to the plate resulting in final concentrations $(\mu \mathrm{g} / \mathrm{mL})$ of $200,150,100,50,25,12.5,10$, and 5 . Both the crude extracts and the fractions were dissolved in sterile DMSO, and tested against the pathogenic bacterial strains. Each of the test metabolites solution was added a volume of $2.5 \mu \mathrm{L}$ to the respective wells. Pathogenic bacterial cultures were grown over-night and diluted by sterile nutrient broth and measured to a specific OD of 0.00075 in a spectrophotometer. In each well, $97.5 \mu \mathrm{L}$ of bacterial suspension was added, making the final test volume in each well to $100 \mu \mathrm{L}$. Ciprofloxacin was used as a positive control. For sterility control, all the test materials were added, and sterile nutrient broth was added instead of bacterial suspension to check whether the test materials is sterile. For negative control, only bacterial suspensions were added to the wells to check whether the bacteria were growing or not. To check the solvents (water and DMSO) were not inhibiting growth of bacteria, another control 
were used with water and DMSO were added in respective wells and bacterial suspension to them. Resazurin solution was prepared at $0.01 \%$ concentration with sterile water. A volume of $4 \mu \mathrm{L}$ was added to each well (except the blank) and mixed well.

Plates were incubated at $37^{\circ} \mathrm{C}$ overnight and any color change was detected visually and measured in an ELISA microplate reader.

\section{Minimum Inhibitory Concentration (MIC)}

We have calculated the MIC of those test metabolites, which gave positive results in the antibacterial assay. Different concentration of the extract e.g. 10, 15, 20, 25, 50, 100, 150, and $200 \mu \mathrm{g} / \mathrm{mL}$ were prepared in DMSO. These different concentrations were added to nutrient broth containing respective test tubes and a fixed volume of bacterial cultures. The culture tubes were then incubated at $37^{\circ} \mathrm{C}$ overnight. After proper incubation, $100 \mu \mathrm{L}$ of cultures were picked up from each test tube and spread on Nutrient Agar (NA) plates and incubated at $37^{\circ} \mathrm{C}$ for overnight. MIC value was calculated using the colony-forming unit (CFU) counting method. To validate the data, MIC was also calculated using a microtiter plate-based anti-microbial assay.

\section{RESULTS}

Bishnupur monuments are famous terracotta temples, and the nature of substratum in these temples varies from bare rocks to terracotta tiles and sculptures. In summer, the temperature on the surface of the monument goes above $60^{\circ} \mathrm{C}$ and along with high light intensity, UV and extreme dryness make it an extreme environment: three Anabaena sp. [Anabaena sp. (VBCCA 052002), Anabaena sp. (VBCCA 052 009), and Anabaena sphaerica (VBCCA 052 010)] are the predominant cyanobacteria in these terracotta moments forming black brownish crust (Fig. 1). Since these cyanobacteria were isolated from the extreme habitat of terracotta monuments with exposure to high light, UV, and desiccation, we carried out the

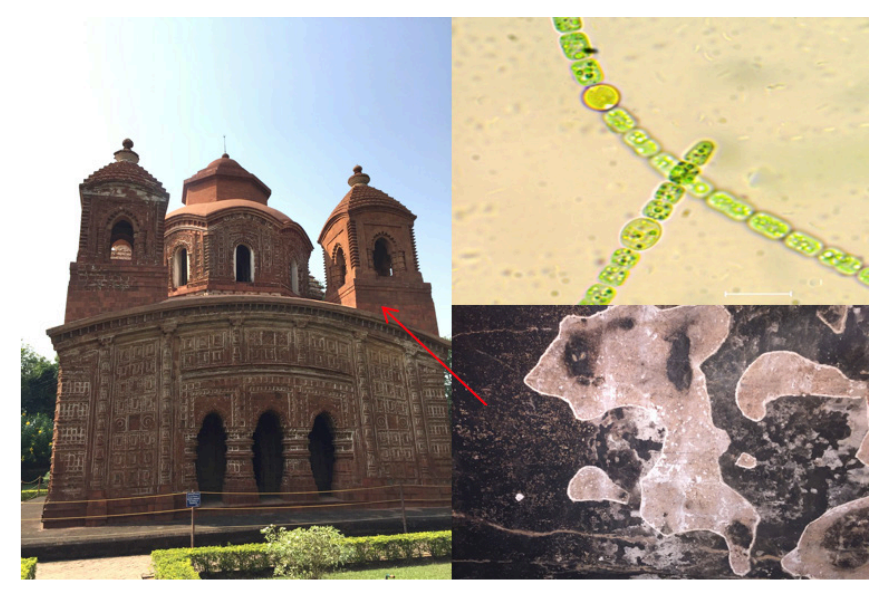

Fig. 1: Figure showing the growth of Anabaena sp. on the terracotta monuments of Bishnupur anti-microbial activity of these cyanobacterial extracts against some gram-positive and gram-negative bacteria. Fig. 2 showing the zone of inhibition (in $\mathrm{mm}$ ) of different solvent extract of three Anabaena sp. on the test pathogenic bacteria Staphylococcus aureus, Salmonella typhimurium, Staphylococcus aureus, Listeria monocytogens, and E. coli.

The results indicated that ethyl acetate extract and ethanol extract of Anabaena sp. (VBCCA 052002) have the highest antibacterial activity against Staphylococcus aureus, Salmonella typhimurium, Staphylococcus aureus and E. coli respectively. In the water extract no antibacterial activity observed against the tested organisms. In ethyl acetate extract of Anabaena sp. (VBCCA 052002) maximum zone of inhibition $19.07 \mathrm{~mm}$ was found against Staphylococcus aureus and $13.33 \mathrm{~mm}$ against Salmonella typhimurium, followed by the ethanol extract of Anabaena sp. (VBCCA 052002) was detected

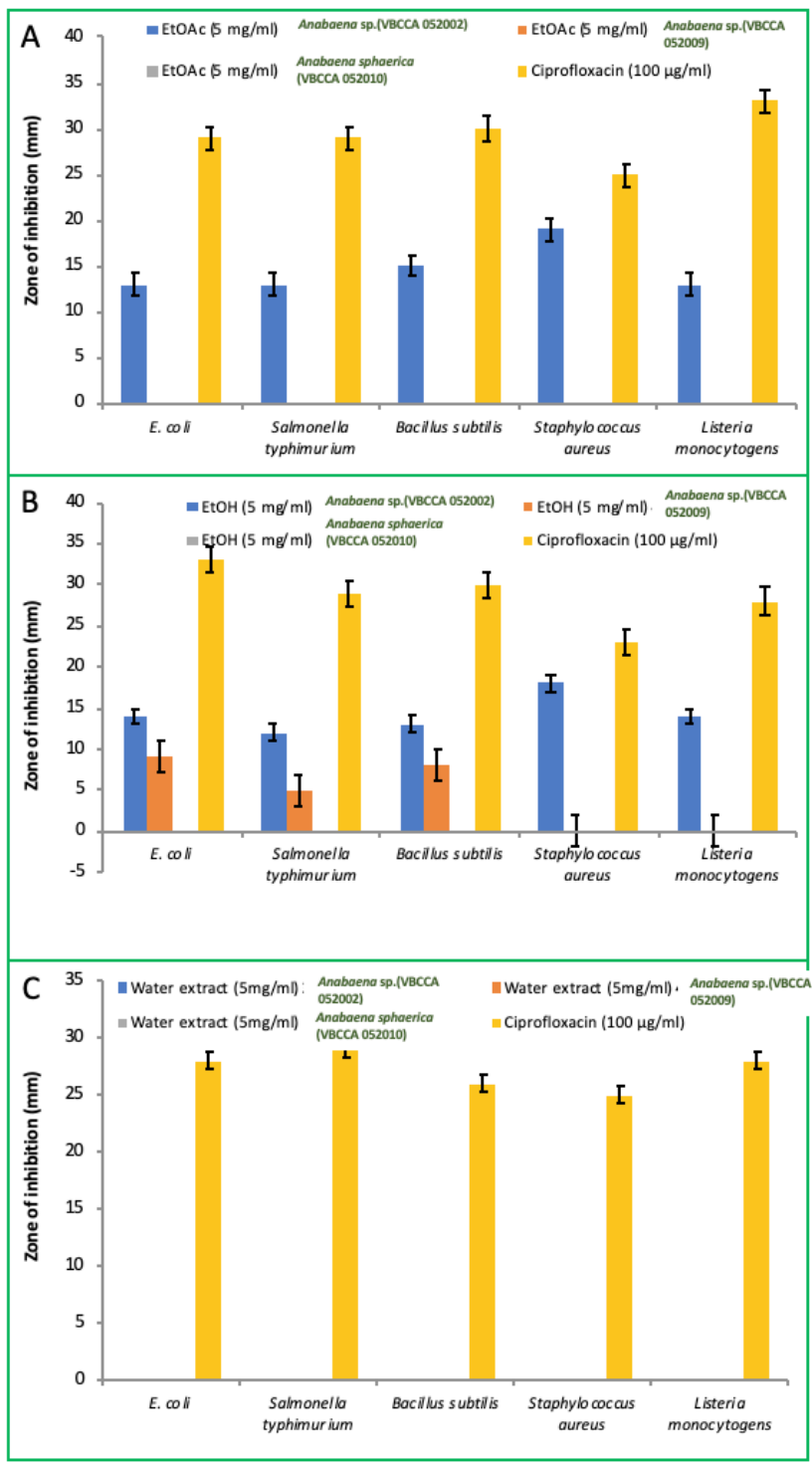

Fig. 2: Anti-microbial activity of Anabaena sp. isolated from terracotta monuments of Bishnupur. 


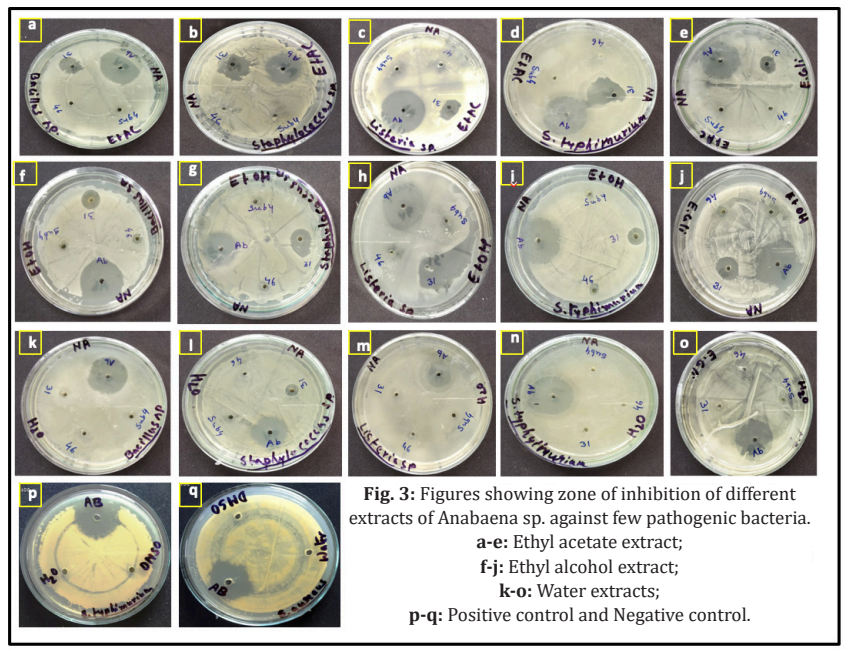

Table 1. Data were showing a growth of S. aureus and S. typhimurium in different test concentrations for calculation of MIC.

\begin{tabular}{lll}
\hline & CFU $/ \mathrm{mL}$ & \\
\hline $\begin{array}{l}\text { Concentration } \\
(\mathrm{ug} / \mathrm{mL})\end{array}$ & $\begin{array}{l}\text { Staphylococcus } \\
\text { aureus }\end{array}$ & $\begin{array}{l}\text { Salmonella } \\
\text { typhimurium }\end{array}$ \\
\hline Control & $7.8 \times 10^{10}$ & $1.7 \times 10^{10}$ \\
10 & $8.6 \times 10^{9}$ & $1.3 \times 10^{10}$ \\
15 & $1.9 \times 10^{9}$ & $2.8 \times 10^{9}$ \\
20 & $1.9 \times 10^{9}$ & $6.2 \times 10^{8}$ \\
25 & $2.0 \times 10^{8}$ & $5.1 \times 10^{7}$ \\
50 & $1.9 \times 10^{4}$ & $1.1 \times 10^{6}$ \\
100 & 0 & $1 \times 10^{2}$ \\
150 & 0 & 0 \\
200 & 0 & 0 \\
\hline
\end{tabular}

18.22 mm against Staphylococcus aureus and $14.19 \mathrm{~mm}$ against E. coli. The ethanolic extract of Anabaena sp. (VBCCA 052009) showed minimum sensitivity in terms of inhibition zone against Bacillus subtilis, E. coli, and Salmonella typhimurium (Fig. 3). To confirm the results obtained in the anti-microbial test using agar diffusion method we further carried out the sensitive resazurin based anti-microbial assay in microtiter platesto calculate the MIC. Resazurin is an oxidation-reduction indicator and can indicates microbial growth in the plate at a very low concentration of the bioactive compounds in respect to color which was measured in a ELISA plate reader. Results obtained from agar diffusion method and the resazurin based microtiter plate-based method indicate MIC values of ethyl acetate extract of Anabaena sp. (VBCCA 052002) were 100 $\mu \mathrm{g} / \mathrm{mL}$ and $150 \mu \mathrm{g} / \mathrm{mL}$ against Staphylococcus aureus and Salmonella typhimurium (Table 1, Fig. 4). The result indicates out of the three Anabaena sp. tested ethyl acetate extract of Anabaena sp. (VBCCA 052002) is having good anti-microbial activity against $S$. aureus and $S$. typhimurium.

\section{Discussion}

In the microbial population, cyanobacteria considered being one of the potential organism for the development of novel antibiotics. Anabaena is a filamentous, heterocyst-

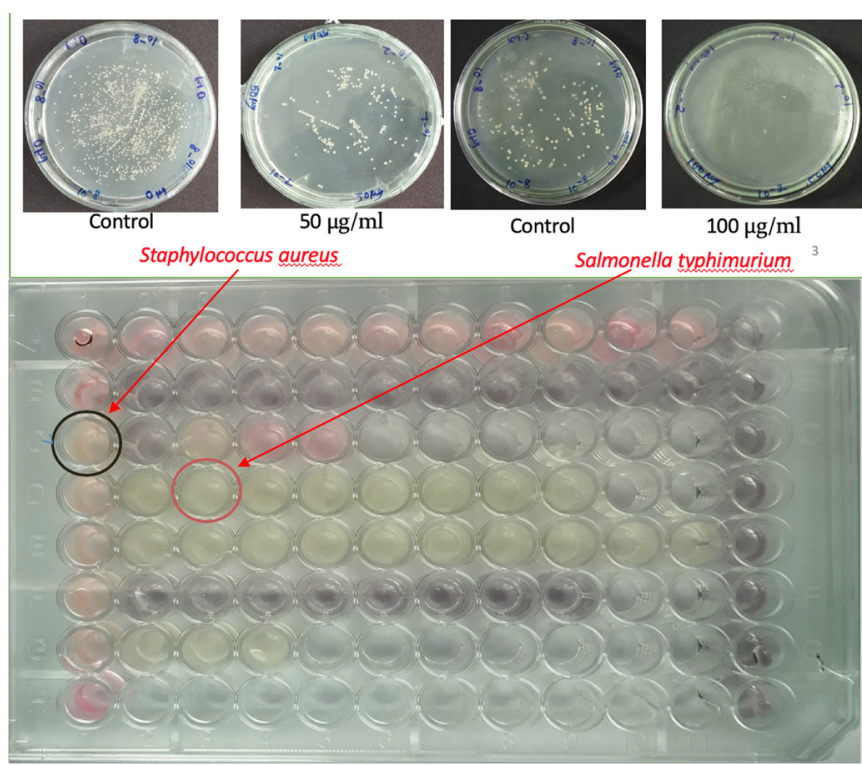

Fig. 4: Figure showing sensitive resazurin based anti-microbial assay for conformation of anti-microbial assay of Anabaena sp. extracts.

forming cyanobacterium having proven antibacterial activity. Heidari et al. (2012) ${ }^{[14]}$ reported that the ethanolic extract of Anabena circinalis have the antibacterial activity against Serratia marcescens, E. coli, Klebsiella pneumonia and the fungus Aspergillus flavus. Abdel-Raouf et al. 2011 ${ }^{[15]}$ also reported antibacterial activity against Sarcina maxima, and Micrococcus kristinae, Klebsiella pneumoniae, as well as against the filamentous fungus Aspergillus flavus. Bhateja et al. 2006 ${ }^{[16]}$ reported organic extracts of Anabaena virabilis showed activity against Staphylococcus aureus. Though few Anabaena sp. have been already tested for anti-microbial properties, subaerial cyanobacteria never been evaluated for its anti-microbial potential and our report of anti-microbial properties against two antibiotic-resistant bacteria Staphylococcus aureus and Salmonella typhimurium shows quite promising results. How the bioactive molecules help the cyanobacteria in surviving the stress condition is not well known, but since the cyanobacteria has wide biological adaptations and tolerance to environmental stress, some of these compounds might be produced in an attempt to confer advantages for their survival. The cyanobacterium Nostoc commune produces a novel antibacterial compound, called Noscomin, which is a diterpenoid. ${ }^{[17]}$ Though in the present study, we have not chemically characterized the antibacterial compound of the Anabaena sp. This is our first attempt to evaluate the antibacterial activity of subaerial cyanobacteria from ancient monuments, which is quite promising.

\section{ACKNOWLEDGMENT}

The authors gratefully acknowledge funding from West Bengal Department of Science and Technology (Project no. ST/P/S\&T/1G-13/2018). SB thanks to UGC for Rajiv 
Gandhi National Fellowship and SS thanks to DST Govt. of India for INSPIRE fellowship. The authors also thank the Head of the Departments of Botany, Visva-Bharati (A Central University), Santiniketan for providing laboratory facilities.

\section{REFERENCES}

1. Abed RM, Dobretsov S, Sudesh K. Applications of cyanobacteria in biotechnology. Journal of applied microbiology. 2009;106(1):1-12.

2. Ramamurthy V, Raveendran S, Thirumeni S, Krishnaveni S. Antimicrobial activity of heterocytic cyanobacteria. Int. J. Adv.Lif. Sci. 2012:1:32-39.

3. Carr NG, Whitton BA. The biology of cyanobacteria. Blackwell Scientific Publications, Oxford; 1982.

4. De Philippis R, Vincenzini M. Exocellular polysaccharides from cyanobacteria and their possible applications. FEMS Microbiology Review. 1998;22:151-175.

5. De Philippis R, Sili C, Paperi R, Exopolysaccharide-producing cyanobacteria and their possible exploitation: A review. Journal of Applied Phycology. 2001;13:293

6. Munro MHG, Blunt JW Marine Lit. University of Canterbury. 2009. http://pubs.rsc.org/marinlit.

7. Rippka R, Deruelles J, Waterbury JB, Herdman M, Stanier RY Generic assignments, strain histories and properties of pure cultures of cyanobacteria. Journal of General Microbio1ogy. 1979;111:1-61

8. Desikachary TV. Cyanophyta. Indian Council of Agricultural Research. New Delhi. 1959. pp 700.

9. Anagnostidis K, Komárek J. Modern approach to the classification system of the cyanophytes 3: Oscillatoriales. Algological studies. 1988. 50/53:327-472.

10. Anagnostidis K, Komárek J. Modern approach to the classification system of the cyanophytes 5: Stigonematales. Algological studies. 1990. 86:1-74.

11. Komárek J. Studies on the cyanophytes (cyanobacteria, cyanoprokaryota) of Cuba: (11) Freshwater Anabaena species.Preslia. 2005; 77(2): 211-234.

12. Fernandez-Garayzabal, JF, Delgado C, Blanco M, Vázquez-Boland JA Briones V, Suárez G, Dominguez L. Role of potassium tellurite and brain heart infusion in expression of the hemolytic phenotype of Listeria spp. on agar plates. Applied Environmental microbiology. 1992;58(1):434-438.

13. Sarker SD, Nahar L, Kumarasamy Y. Microtiter plate-based antibacterial assay incorporating resazurin as an indicator of cell growth, and its application in the in vitro antibacterial screening of phytochemicals. Methods. 2007;42:321-24.

14. Heidari A, Keshavarz H, Shojaee S, Raeisi A, Dittrich S. In vivo susceptibility of Plasmodium vivax to chloroquine in Southeastern Iran. Iranian Journal of Parasitology 2012;7:8-14

15. Abdel-Raouf N, Ibraheem IBM, Abdel-Tawab S, Naser YAG. Antimicrobial and anti-hyperlipidemic activities of isolated quercetin from Anabaena aequalis. Journal of Phycology. 2011;47:955-962.

16. Bhateja P, Mathur T, Pandya M, Fatma T, Rattan A. Activity of blue green microalgae extracts against in vitro generated Staphylococcus aureus with reduced susceptibility to vancomycin. Fitoterapia. 2006;77:233-235.

17. Jaki B, Orjala J, Sticher O. A novel extracellular diterpenoid with antibacterial activity from the cyanobacterium Nostoc commune. Journal of Natural Product. 1999;62:502 503.

HOW TO CITE THIS ARTICLE: Bhakat S, Saha S, Mandal S, Rath J. Antibacterial activity of desiccated cyanobacterium Anabaena sp. isolated from terracotta monuments of Bishnupur, West Bengal. Int. J. Pharm. Sci. Drug Res. 2020;12(2):94-98. D0I: 10.25004/IJPSDR.2020.120201 